\title{
Getting the right PPE: five minutes with . . . Sarah Hallett
}

\author{
The chair of the BMA Junior Doctors Committee discusses what to do if you think you might not \\ have the proper protective equipment
}

\begin{abstract}
Abi Rimmer
The BMJ

"We've heard that deliveries of personal protective equipment (PPE) are being rolled out to hospitals and GP practices, but currently we know that many doctors on the front line still don't have adequate access to proper PPE.

"The BMA has made strong calls for the government to resolve the matter immediately. ${ }^{1}$ We have concerns that without proper protection, some doctors could-as a direct consequence of their work-become ill, and that in some cases this could be fatal. If you're concerned that you are being asked to see patients who have or are suspected of having covid-19, without the correct PPE for that particular situation, this should be raised immediately with management and with the BMA.

"Doctors in hospital have every right to request to be moved to a low risk area or to provide patient care that doesn't expose them to becoming infected with covid-19 if adequate PPE isn't available.

"GPs with patients who still need face to face care need to think carefully about the level of risk they are exposing themselves and other patients to if they give that care without protection. There are limits to the risks that doctors should expose themselves to and it isn't fair for doctors, or their patients, to expect them to go beyond those limits.
\end{abstract}

"Another matter doctors have raised with us is the long hours they're working and whether hospitals should provide them food and somewhere to rest.

"Junior doctors should make sure they're eating and drinking sufficiently during their shifts as well as taking regular rest breaks. Under the existing contract, trainees in England are entitled to hot and cold food and drink when working overnight, as well as access to a space where they can eat or take a break during their shift and facilities where they can rest after their shift has ended if they feel unable to travel home because of tiredness.

"As well as this, the BMA has backed calls for trusts to provide 24 hour access to food for doctors, and to consider further arrangements where staff are working longer shifts to ensure sufficient and adequate rest space is available - this could involve the repurposing of offices into rest spaces for instance."

You can read Sarah Hallett's answers to more questions on how the covid-19 pandemic might affect trainees here: www.bmj.com/content/368/bmj.m1276

Newman M. Covid-19: doctors' leaders warn that staff could quit and may die over lack of protective equipment. BMJ 2020;368:m1257. 10.1136/bmj.m1257 32217522 Published by the BMJ Publishing Group Limited. For permission to use (where not already granted under a licence) please go to http://group.bmj.com/group/rights-licensing/ permissions 